\title{
Beneficios y contingencias aduaneras derivadas de los acuerdos comerciales y tratados de libre comercio
}

\author{
José Luis Sorogastúa Ruffner
}

Los acuerdos comerciales y los tratados de libre comercio que viene suscribiendo nuestro país con distintos países y bloques económicos brindan a las empresas peruanas, entre otros aspectos, una oportunidad de ingresar a nuevos mercados con mayor poder adquisitivo, a fin de ofrecer sus productos a precios más competitivos, $\mathrm{y}$, asimismo, la posibilidad de abastecerse de mejores productos a costos más bajos.

El ingreso a precios más competitivos se logra aplicando rebajas arancelarias (menor pago de derechos arancelarios) a los productos exportados y que posteriormente son importados en los países de destino, y, a su vez, el abastecimiento con productos a costos más bajos se obtiene aplicando dichas rebajas arancelarias al momento de la importación de los mismos de terceros países al Perú.

La aplicación de las rebajas arancelarias se logra cumpliendo con tres requisitos fundamentales, los cuales se encuentran regulados (con algunas variaciones) en los acuerdos comerciales y los tratados de libre comercio suscritos por nuestro país. Estos tres requisitos son: la negociación, la expedición directa y el origen.

La negociación implica que la subpartida arancelaria (del sistema armonizado) del producto se encuentre negociada y tenga una determinada rebaja arancelaria, la cual puede ser total, parcial y, a la vez, inmediata o gradual. 
Sobre el particular, corresponde indicar que la clasificación arancelaria internacional de un producto (mercancía susceptible de ser comercializada) se lleva a cabo a nivel de subpartida arancelaria del sistema armonizado, la cual está compuesta por seis dígitos (06); es decir, todo producto debe compartir a nivel internacional el mismo código de seis dígitos, lo cual permite a los diferentes países llevar a cabo las negociaciones internacionales de desgravación sobre productos plenamente identificados.

De esta manera, a efectos de una correcta acogida a los beneficios arancelarios de un acuerdo o tratado, corresponde, en primer lugar, determinar cuál es la subpartida arancelaria (del sistema armonizado) que le corresponde al producto que se desea comercializar, y luego determinar si dicha subpartida ha sido negociada en algún acuerdo o tratado con el país al cual se va a exportar o del cual se va a importar.

En los acuerdos comerciales o tratados de libre comercio, los países negocian la desgravación de los productos clasificándolos en canastas o categorías de desgravación, a efectos de diferenciar a aquellos productos a los cuales se quiere otorgar una rebaja arancelaria de manera total o parcial, y de manera inmediata o gradual.

Se debe tener presente que en la negociación de los acuerdos y tratados, las partes evalúan qué productos pueden generar mayor o menor incidencia en las industrias nacionales, y en atención a ello definen la canasta o categoría que corresponde a cada uno de ellos. De esta forma, además de determinar la subpartida que le corresponde al producto, se debe determinar en qué categoría o canasta de desgravación se encuentra dicha subpartida. También se debe considerar que al momento de negociarse un determinado acuerdo o tratado, los productos tienen, en cada uno de los países que están negociando, un determinado arancel, y en atención a ello el acuerdo o tratado determina un arancel base sobre el cual se aplicarán las desgravaciones en sus diferentes categorías o canastas.

Por su parte, la expedición directa implica que los productos deben, como regla general, transportarse desde un territorio de un país parte, directamente hasta el territorio del otro país parte, sin pasar por el territorio de ningún tercer país que no sea parte. Sin embargo, existen excepciones a esta regla general, y bajo ciertas circunstancias se permite el traslado por un tercer país no parte, siempre que el producto se mantenga bajo el control de la autoridad aduanera de este tercer país y no se 
lleve a cabo ninguna operación sobre el producto que implique una alteración al mismo; es decir, pueden efectuarse operaciones tales como el transbordo, tránsito, etc.

El tercer requisito es el origen, y consiste en acreditar que el producto ha cumplido con las reglas que lo califican como originario del país parte y que, adicionado a los dos requisitos anteriores (negociación y expedición directa), le permite acceder a los beneficios arancelarios del acuerdo o tratado.

Las reglas de origen pueden cambiar entre los diferentes acuerdos y tratados, pero son seis de ellas las que con un menor o mayor grado de variación, se encuentran en todos ellos.

- La primera regla de origen es aquella que señala que un producto obtenido en un país parte es originario de dicho país. Esta regla se aplica para animales, plantas y minerales que han nacido, han sido capturados o son obtenidos en el territorio del país parte.

- La segunda regla de origen es aquella que indica que un producto fabricado en el territorio de un país parte, a partir de materias primas e insumos que son también originarios de dicho país parte, es originario de ese país.

Las siguientes reglas de origen se aplican a los productos fabricados en el territorio de un país parte, a partir de ciertas materias primas e insumos que no son originarios de dicho país parte.

- Así, tenemos la regla del salto (o cambio) de partida, la cual señala que cuando las materias primas e insumos que no son originarios de dicho país parte tienen una subpartida arancelaria (seis dígitos) distinta al producto exportado, este último es originario de dicho país. Esta regla también puede exigir que las materias primas e insumos que no son originarios de dicho país parte, solo cumplan con el salto o cambio del capítulo o de la partida (dos o cuatro dígitos, respectivamente), respecto del capítulo o partida del producto a exportar.

- Otra regla de origen es la regla del valor del contenido regional, conforme a la cual, aplicada una fórmula, de obtenerse un porcentaje igual o mayor al indicado para la subpartida de ese producto, este deviene en originario del país.

La fórmula es la siguiente:

VCR: (VT - VMN) X 100 / VT 
Donde:

VCR: Valor de contenido regional expresado en porcentaje.

VT: Valor de transacción del bien.

VMN: Valor de materiales no originarios utilizados en la producción del bien.

- Una quinta regla de origen es la regla del minimis, la cual señala que cuando el valor de las materias primas e insumos no originarios no supera un determinado porcentaje del valor del producto final, este último tiene la condición de originario.

- Finalmente, una sexta regla de origen, común a todos los acuerdos o tratados, es la regla de la acumulación, en virtud de la cual las materias primas e insumos que son originarios de un país parte se consideran originarios respecto de los productos fabricados en el otro país parte. Esta regla puede también regularse bajo la figura de la acumulación extendida, la cual permite considerar como originaria una materia prima o insumos de un tercer país que no es parte de un determinado acuerdo o tratado, pero sí es parte con ambos países en otro acuerdo o tratado.

Es importante tener presente que estas diferentes reglas anteriormente anotadas ( $u$ otras que pueden regularse en determinado acuerdo o tratado) varían en atención a las diferentes subpartidas; es decir, existirán partidas a las que se podrán aplicar todas ellas para determinar si el producto negociado en dicha partida es originario, como también habrá subpartidas a las cuales se aplicará solo alguna de ellas.

Igualmente, debe entenderse que estos tres requisitos (negociación, expedición directa y reglas de origen) variarán dependiendo del acuerdo o el tratado. En ese sentido, cada vez que se busque establecer si un determinado producto puede acogerse a los beneficios arancelarios de un acuerdo o tratado, se deberán analizar sus normas puntuales, toda vez que puede ocurrir que un mismo producto, fabricado en un mismo país, puede resultar ser originario para ingresar a un país y no originario para otro.

Ahora bien, a pesar de que los acuerdos comerciales o tratados de libre comercio pueden otorgar beneficios, lo cierto es que también un acogimiento indebido a los mismos puede acarrear contingencias, las cuales lamentablemente no resultan a nuestro entender del todo precisas, más aún cuando el importador se acoge a un beneficio arancelario 
en atención a la documentación proporcionada por su proveedor del país parte, particularmente el certificado de origen, que acredita que dicho producto califica como originario de ese país.

En efecto, actualmente el Ministerio de Comercio Exterior y Turismo (Mincetur) ha iniciado verificaciones de origen para determinar si los productos que vienen ingresando al país, gozando de un determinado beneficio arancelario derivado del acogimiento al Acuerdo de Promoción Comercial o Tratado de Libre Comercio con los Estados Unidos, son efectivamente originarios de dicho país. Para tal efecto, el Mincetur llevó a cabo una investigación respecto de un determinado número de operaciones de exportación realizadas por un determinado exportador hacia el Perú en un determinado lapso. Y como consecuencia de dichas verificaciones de origen, el Mincetur ha determinado en ciertos casos que el proveedor del país de origen no ha podido demostrar y acreditar que, pese a que emitió un certificado de origen, los productos verificados son efectivamente originarios de dicho país. De esta manera, Mincetur ha desconocido la condición de originario de dicho producto y ha adoptado las acciones que considera pertinentes.

A la fecha, las acciones que viene tomando el Mincetur cuando detecta tal situación son, en primer lugar, emitir una resolución (de carácter viceministerial) que cierre el trato preferencial al exportador; es decir, mediante dicha resolución se dispone impedir que el exportador siga calificando sus exportaciones hacia el Perú como originarias de dicho país, y en segundo lugar, oficia a la Superintendencia Nacional de Aduanas y de Administración Tributaria (Sunat) para que haga efectiva dicha medida.

No obstante, cabe resaltar que cuando la Sunat dispone aplicar tal medida (cerrar el trato preferencial) determina, además del cierre del trato preferencial al exportador, otras acciones respecto de los importadores que adquirieron productos a dicho exportador y que en su momento se acogieron a los beneficios de rebaja arancelaria que el certificado de origen proporcionado por el exportador les otorgaba.

En efecto, la Sunat determina que la empresa importadora ha declarado incorrectamente el origen de los productos importados, lo que trae como consecuencia que se dejen de pagar tributos a la importación producto de una rebaja arancelaria que no le corresponde. Asimismo, determina que corresponde la aplicación de derechos antidumping, por cuanto al no haberse acreditado el origen de los productos del país 
exportado, se presume que estos son originarios de un país afecto a dichas medidas. Por último, determina que corresponde la aplicación de una sanción de una multa equivalente al doble de los tributos y recargos (derechos antidumping) dejados de pagar, por haber formulado una declaración incorrecta respecto al origen de los productos.

Es importante anotar que la Sunat dispone la aplicación de las medidas anteriormente indicadas (cobro de tributos, derechos antidumping y multas aduaneras) a todos los importadores que han comprado productos a dicho proveedor extranjero y que se encuentren en la misma subpartida que los productos verificados por el Mincetur.

En ese sentido, como puede observarse, las contingencias que se pueden derivar de una incorrecta calificación de origen de un determinado producto son: en lo que respecta a los exportadores, el cierre de trato preferencial a sus exportaciones al país de destino, y en lo que respecta a los importadores, el desconocimiento del origen por parte de la entidad verificadora de destino (Mincetur) y el posterior cobro por parte de Sunat de los tributos liberados, multas aduaneras y derechos antidumping, esto último en caso de que el producto, cuyo origen no se pueda acreditar, se clasifique en una subpartida afecta a dicha imposición.

Respecto de las contingencias aduaneras anteriormente detalladas, consideramos necesario plantear nuestra disconformidad con las mismas, más aun tomando en cuenta que dichas acciones por parte del Mincetur y la Sunat, son acciones que recién se vienen adoptando como consecuencia de las primeras acciones de verificación de origen realizadas, y que a nuestro entender deben ser reevaluadas a fin de no ocasionar perjuicios indebidos a empresarios que han actuado de buena fe, y para no generar inseguridad jurídica en relación con la aplicación de los acuerdos comerciales y los tratados de libre comercio, que por su naturaleza buscan justamente otorgar seguridad jurídica a los negocios entre los particulares de los países partes.

En efecto, como lo comentamos anteriormente, en la verificación de origen efectuada por el Mincetur, este organismo, al no haberse podido acreditar, a su criterio, el origen de las mercancías desde el país del cual fueron adquiridas y transportadas, y que concedía el beneficio de rebaja arancelaria, dispuso denegar el trato arancelario preferencial a cualquier producto, clasificado en la misma subpartida y exportado por la misma empresa. 
En ese sentido, pese a que el Mincetur en su verificación de origen limita el objeto, el universo de productos y alcance del procedimiento de verificación a los productos que han sido verificados, dicha entidad establece cerrar el trato preferencial para las futuras exportaciones del mismo producto. Por consiguiente, mal hace la Sunat cuando pretende ampliar los efectos de la verificación de origen realizada por el Mincetur a productos que no han sido materia de verificación y respecto de los cuales no se ha efectuado una determinación negativa de origen con base en un procedimiento de verificación, tal como lo establecen el artículo 3 y el numeral 3 del artículo 14 del Decreto Supremo n. ${ }^{\circ}$ 001-2009-Mincetur.

Interpretar lo contrario implicaría extender los alcances del procedimiento de verificación a productos que no fueron debidamente investigados, y con ello a vulnerar el principio de legalidad contemplado en el numeral 1.1 del artículo IV de la Ley n. ${ }^{\circ} 27444$, Ley de Procedimiento Administrativo General, de aplicación supletoria al presente caso, el cual expresamente dispone: "Las autoridades administrativas deben actuar con respeto a la Constitución, la Ley y al derecho, dentro de las facultades que les estén atribuidas y de acuerdo con los fines para los que fueron concebidas...".

Conforme lo señala Morón Urbina:

Si en el derecho privado la capacidad es la regla y la incapacidad es la excepción, en el derecho público la relación es precisamente a la inversa, ya que en resguardo de la libertad individual y derechos de los ciudadanos, la ley no asigna a cada sujeto de derecho, ámbito y fin predeterminado, más bien sus aptitudes se determinan por proposiciones positivas, declarativas y marginalmente limitativas. Como se puede apreciar, las competencias públicas mantienen una situación precisamente inversa, ya que debiendo su creación y subsistencia a la ley, por ende, siempre debe contar con una norma que le señale su campo atributivo, que lógicamente no puede ser ilimitado. (2001, p. 60)

Del mismo modo, continúa diciendo:

Con acierto se señala que mientras los sujetos de derecho privado pueden hacer todo lo que no está prohibido, los sujetos de derecho público sólo pueden hacer aquello que les sea expresamente 
facultado. En otras palabras, no basta la simple relación de no contradicción. Se exige, además, una relación de subordinación. Es decir que para la legitimidad de un acto administrativo es insuficiente el hecho de no ser ofensivo a la ley. Debe ser realizado con base en alguna norma permisiva que le sirva de fundamento. La concepción según la cual el Estado podía hacer todo lo que no le estuviera prohibido, abría un ilimitado campo de acción a su discrecionalidad que le permitía aparecer en todos los espacios francos o silenciados por la ley expresa, con lo cual se toleraba la existencia de actos administrativos sin parámetro de contraste que permita evaluar su legitimidad. (Morón Urbina, 2001, p. 60)

En virtud de ello, de ninguna manera debe interpretarse que la determinación negativa de origen realizada por el Mincetur luego del procedimiento de verificación efectuado a determinados productos en determinadas operaciones de venta, puede extenderse a productos importados vinculados a otras operaciones respecto de las cuales no se ha efectuado procedimiento de verificación de origen alguno, por el solo hecho de tratarse de operaciones que corresponden a ventas efectuadas por el mismo proveedor extranjero y compartir las subpartidas arancelarias de los productos que sí han sido verificados.

A su vez, cabe indicar que el hecho de circunscribir el procedimiento de verificación a un número determinado de productos responde a un criterio de razonabilidad, toda vez que la decisión de la autoridad administrativa debe adaptarse dentro de los límites de la facultad atribuida, a fin de que respondan a lo estrictamente necesario para la satisfacción de su cometido, es decir, para determinar el origen de las mercancías investigadas.

Otro aspecto fundamental que no está siendo tomado en consideración por la Sunat, es que la verificación de origen efectuada por el Mincetur solo puede tener efectos para los productos involucrados en el procedimiento de verificación, o para los productos idénticos que se importen con posterioridad a dicha determinación negativa de origen. Efectivamente, de conformidad con lo dispuesto en el artículo 1.1 de la Ley n. ${ }^{\circ} 27444$, son actos administrativos las declaraciones de las entidades que, en el marco de las normas de derecho público, están destinadas a producir efectos jurídicos sobre los intereses, obligaciones o derechos de los administrados dentro de una situación jurídica concreta. 
En el presente caso, una resolución del Mincetur, emitida en atención a un proceso de verificación de origen, en virtud de la cual se establece una determinación negativa de origen, es una declaración emitida por una entidad del Estado, destinada a producir efectos jurídicos solamente sobre los intereses particulares de las partes involucradas en dicho proceso. En tal sentido, en la medida en que dicha resolución califica como un acto administrativo, se le aplican, entre otros, los requisitos de validez, forma y eficacia contemplados en la Ley de Procedimiento Administrativo General.

Bajo este contexto, se debe indicar que de acuerdo con lo señalado en el artículo 16.1, en concordancia con el artículo 17.1 de la Ley n. ${ }^{\circ} 27444$, el acto administrativo es eficaz a partir de que la notificación legalmente realizada produce sus efectos, salvo cuando la autoridad disponga en el mismo acto que tenga eficacia anticipada a su emisión, lo cual únicamente podrá suceder si dicho acto fuera más favorable a los administrados y siempre que no lesione derechos fundamentales o intereses de buena fe legalmente protegidos de terceros, y que existiera en la fecha a la que pretenda retrotraerse la eficacia del acto el supuesto de hecho justificativo para su adopción.

Como bien lo señala Morón Urbina (2001), la irretroactividad de los actos administrativos es la regla general; no obstante, se contempla el efecto excepcional de la retroactividad del acto hasta momentos anteriores a su emisión. Por su propia naturaleza excepcional, las causales han de aplicarse restrictivamente y previa constitución expresa en la misma decisión administrativa y no en vías de interpretación (pp. 183-185).

De la revisión del artículo 17 de la Ley de Procedimiento Administrativo General, se aprecia que para la retroactividad de un acto administrativo, la Administración debe evaluar la concurrencia de tres requisitos en su decisión:

a. Que el acto sea favorable a los administrados.- Los actos administrativos que pueden ser objeto de efecto retroactivo han de ser de tipo favorable y no de perjuicio para el administrado, pues resulta lógico que si la regla general de la irretroactividad se ha establecido para proteger a los ciudadanos, cuando la protección exige el efecto anticipado, carece de sentido insistir en mantener la regla como garantía de tutelar al particular.

Los actos susceptibles de asumir efecto retroactivo no pueden ser aquellos cuyo contenido jurídico produzcan un efecto desfavora- 
ble en la esfera jurídica del destinatario del acto. Es importante resaltar que el efecto favorable o desfavorable del acto se establece en función de la perspectiva jurídica de los administrados y no desde el punto de vista extrajurídico, como pueden ser los efectos económicos, sociales, políticos, etcétera, del acto administrativo.

b. Que el acto no lesione derechos fundamentales o intereses de buena fe legalmente protegidos de terceros.- Tratándose del interés público, la eficacia retroactiva no puede pretenderse cuando pueda afectar derechos o intereses de terceros que se encuentren protegidos de buena fe.

c. Que el supuesto de hecho justificativo de la dación del acto exista a la fecha en la que pretenda retrotraerse la eficacia del acto.- El requisito objetivo para la dación de un acto administrativo es que el supuesto de hecho de la norma sea real y exista al momento de la decisión. Por ello, es de suyo coherente que si se pretende retrotraer los efectos de decisiones administrativas, a esa misma fecha deben haber existido los supuestos de hecho fundantes de la decisión.

Por un criterio mínimo de prudencia, de respeto a los principios de previsibilidad y buena fe, se estima que una buena práctica administrativa conllevará a que la eficacia anticipada no sea una potestad discrecional de la autoridad, sino una posibilidad a la cual el administrado se pueda acoger cuando tenga los elementos necesarios para ello. En ese sentido, no solo no se puede aplicar lo resuelto por el Mincetur a terceros (importadores) que no formaron parte del proceso, sino que tampoco podría ser aplicado a operaciones de importación de productos que no solo no fueron materia de investigación, sino que además fueron realizadas con anterioridad a la emisión del acto administrativo del Mincetur, incluso con anterioridad a la fecha en que el proceso de investigación se inició.

En efecto, con relación a los requisitos para que un acto administrativo pueda ser aplicado retroactivamente, y en atención al presente acto administrativo del Mincetur, tenemos lo siguiente:

- El acto no es favorable a las empresas importadoras.

- El supuesto de hecho justificativo a la dación del acto no existía a la fecha en la que pretende retrotraerse la eficacia del acto, la fecha en que los importadores adquirieron los productos o los importaron. 
- El acto lesiona la buena fe de los importadores, toda vez que contrataron con el proveedor sin tener conocimiento de que las exportaciones efectuadas por dicha empresa se encontraban sujetas a un procedimiento de verificación por haberse generado dudas respecto del origen de sus mercancías.

$\mathrm{Al}$ respecto, si el Mincetur hubiese deseado darle carácter público y general a su acto administrativo, en atención a lo dispuesto en el numeral 6 del artículo 3.2 del Acuerdo de Promoción Comercial suscrito entre Perú y Estados Unidos, en concordancia con el artículo 10.9 del Decreto Supremo n. ${ }^{\circ}$ 001-2009-Mincetur, debió publicar el nombre de dicha empresa en la medida en que esta supuestamente había fallado en demostrar que producía o era capaz de producir mercancías originarias de Estados Unidos.

Definitivamente, la publicidad de dicha información es fundamental, toda vez que genera mayor previsibilidad, certeza y seguridad jurídica en los importadores, los cuales tendrán mayor confianza al negociar sus transacciones con proveedores americanos en aplicación del Acuerdo de Promoción Comercial suscrito con los Estados Unidos.

Si bien el capítulo 19 de dicho acuerdo comercial regula la transparencia de las leyes, reglamentos, procedimientos y resoluciones administrativas de carácter general, consideramos que sus disposiciones también resultarían de aplicación a los procedimientos de verificación de origen, pese a su carácter particular, toda vez que, mediante estos, se pretende afectar y, peor aún, sancionar no solo a la parte que incumplió con los requisitos de origen de las mercancías, sino también a los terceros de buena fe que contrataron con esta última.

Dicho artículo señala lo siguiente:

\section{[...] 19.2. Publicación}

1. Cada Parte se asegurará de que sus leyes, reglamentos, procedimientos y resoluciones administrativas de aplicación general referentes a cualquier asunto comprendido en este Acuerdo, se publiquen prontamente o de otra forma sean puestos a disposición para conocimiento de las personas y Partes interesadas.

2. En la medida de lo posible, cada Parte deberá:

(a) Publicar por adelantado cualquier medida que se proponga adoptar, $\mathrm{y}$ 
(b) Brindar a las personas y partes interesadas oportunidad razonable para formular observaciones sobre las medidas propuestas.

19.4. Procedimientos administrativos

Con el fin de administrar en forma compatible, imparcial y razonable todas las medidas de aplicación general que afecten las materias que cubre este Acuerdo, cada Parte se asegurará de que, en sus procedimientos administrativos en que se apliquen las medidas mencionadas en el Artículo 19.2 respecto a personas, mercancías o servicios en particular de otra Parte en casos específicos:

(a) Siempre que sea posible, las personas de la otra Parte que se vean directamente afectadas por un procedimiento, reciben, conforme a las disposiciones internas, aviso razonable del inicio del mismo, incluidas una descripción de su naturaleza, la exposición del fundamento jurídico conforme al cual el procedimiento es iniciado, y una descripción general de todas las cuestiones controvertidas.

(b) Cuando el tiempo, la naturaleza del procedimiento y el interés público lo permitan, dichas personas reciben una oportunidad razonable para presentar hechos y argumentos en apoyo de sus pretensiones, previamente a cualquier acción administrativa definitiva.

(c) Sus procedimientos se ajusten a la legislación interna [...]. (Acuerdo, 2009)

En caso contrario, los importadores de buena fe que creen adquirir productos originarios de Estados Unidos (o de los diferentes países o bloques económicos con los cuales se han establecido acuerdos comerciales o tratados de libre comercio), según la información proporcionada por sus proveedores, se verán sumamente perjudicados con las medidas adoptadas por la Sunat, la cual no toma en cuenta las circunstancias producidas, sino que actúa con objetivos meramente recaudatorios.

Por otro lado, adicionalmente a lo antes señalado, tampoco procede pretender efectuar el cobro de tributos, derechos antidumping o multas aduaneras a los importadores, cuando el acto administrativo del Mincetur en atención al cual se culmina la verificación de origen resuelve denegar el trato arancelario preferencial, mas no ordena el cobro de ningún tributo o deuda. 
En ese sentido, la denegatoria del trato arancelario preferencial resultaría aplicable a la importación de productos idénticos a los que fueron objeto del procedimiento de verificación de origen vendidos por el proveedor investigado que se efectúen con posterioridad a la emisión de dicho acto administrativo, impidiéndoles acogerse a las rebajas arancelarias otorgadas por el Acuerdo.

Ello se condice con lo dispuesto en el artículo 20.1 del Decreto Supremo n. ${ }^{\circ}$ 001-2009-Mincetur, el cual faculta al Mincetur a instruir a la Administración Aduanera para que (i) deniegue la solicitud de trato preferencial, o (ii) cobre los tributos dejados de pagar relacionados con dicha importación, cuando determine que una mercancía textil importada no es originaria de Estados Unidos.

Como se puede observar, tales medidas son excluyentes entre sí, es decir, o bien se deniega la solicitud de trato preferencial, o bien se cobran los tributos dejados de pagar relacionados con la importación de un producto textil calificado como no originario en virtud de lo resuelto en un procedimiento de verificación, pero de ninguna manera dicha entidad podrá adoptar ambas medidas en forma conjunta.

En atención al pretendido cobro de derechos antidumping, el sustento de Sunat radica en que mientras los productos no califiquen como originarios del país parte, se presume que provienen de un país afecto a dicha imposición. No obstante, la Sunat no puede presumir que un producto que supuestamente no califica como originario de un país, es originario de un país afecto a los derechos antidumping o compensatorios, resultando fundamental que tal aseveración se encuentre respaldada por una norma con rango legal, a efectos de cumplir con nuestro derecho a una debida motivación.

Igualmente, tampoco resulta procedente el cobro de la multa aduanera equivalente al doble de los tributos y recargos (derechos antidumping) dejados de pagar, toda vez que no se ha formulado declaración incorrecta alguna respecto del origen de las mercancías provenientes de un determinado país, en la medida en que la descalificación de origen formulada por el Mincetur no le resulta de aplicación, toda vez que dicha entidad solo ha denegado tal originalidad a los productos que fueron materia de verificación, resolviendo además no el cobro de tributos sino el cierre del trato preferencial. 
Ahora bien, cabe indicar que de conformidad con lo establecido en el artículo 26 del reglamento que implementa el Régimen de Origen establecido en el Acuerdo de Promoción Comercial suscrito entre el Perú y los Estados Unidos, aprobado mediante Decreto Supremo n. ${ }^{o}$ 003-2009-Mincetur, un importador podrá ser sancionado cuando se compruebe que incurrió en negligencia, negligencia sustancial o fraude, al solicitar el trato arancelario preferencial.

Ello se condice con lo dispuesto en el numeral 1.4 del artículo IV, en concordancia con el numeral 3 del artículo 230 de la Ley n. ${ }^{\circ} 27444$, los cuales establecen que en aplicación del principio de razonabilidad, las decisiones de la autoridad administrativa, cuando creen obligaciones, califiquen infracciones, impongan sanciones o establezcan restricciones a los administrados, deben adoptarse dentro de los límites de la facultad atribuida y manteniendo la debida proporción entre los medios a emplear y los fines públicos que deba tutelar, a fin de que respondan a lo estrictamente necesario para la satisfacción de su cometido, y que para su determinación se consideren criterios como la existencia o no de intencionalidad, el perjuicio causado, las circunstancias de la comisión de la infracción y la repetición de la comisión de la infracción.

En el presente caso, la Sunat, al calificar la supuesta infracción y establecer la sanción, debe evaluar las circunstancias anteriormente descritas, así como la falta de intencionalidad y conocimiento de los importadores respecto de las irregularidades cometidas por el proveedor en cuanto a la acreditación del origen de las mercancías fiscalizadas.

Por otro lado, es menester enfatizar que la actuación de la Sunat vulnera el principio de causalidad dispuesto en el numeral 2 del artículo 230 de dicha norma, toda vez que la responsabilidad respecto a la no acreditación de la originalidad americana de las mercancías no recae en quien realiza la conducta omisiva o activa constitutiva de infracción sancionable, sino que, por el contrario, se pretende sancionar a los importadores cuyas importaciones no formaron parte del procedimiento de verificación y por consiguiente no han sido descalificadas como originarias del país parte.

En conclusión, si bien los acuerdos comerciales y los tratados de libre comercio suscritos por nuestro país con distintos países y bloques económicos, brindan a las empresas peruanas oportunidades de negocios al ingresar a nuevos mercados con mayor poder adquisitivo, para ofrecer sus productos a precios más competitivos, así como la posibilidad 
de abastecerse de mejores productos a costos más bajos, es importante saber aprovechar esas oportunidades con la diligencia debida, a efectos de que los beneficios no se conviertan en contingencias que, como hemos observado, pueden ser determinadas, a nuestro criterio, de manera ilegal y extensiva por parte de Sunat.

La diligencia debida a la que nos referimos, consiste en tener un adecuado conocimiento de cuáles son los requisitos legales que se deben cumplir como exportador o como importador para efectuar un adecuado acogimiento al acuerdo comercial o tratado de libre comercio con el país que se está comercializando (exportando o importando los productos). Dichos requisitos consisten básicamente en verificar los aspectos desarrollados en el presente artículo: la negociación, la expedición directa y el origen, y determinar adecuadamente que el producto (exportado o importado) cumple con ellos, tomando en cuenta las reglas que se aplican para cada acuerdo o tratado en particular y para cada producto en específico.

Asimismo, en el caso particular de los importadores, se requiere que el proveedor del producto, encargado de obtener la certificación de origen, pueda demostrar, a requerimiento, los documentos que acreditan tal cumplimiento y que eventualmente podrían ser requeridos en una futura fiscalización a cargo de una autoridad peruana o del país de origen.

Finalmente, el presente artículo busca también generar debate con relación a las consecuencias jurídicas derivadas de los trámites de verificación de origen que ha iniciado el Mincetur y respecto de los alcances que dichos procedimientos tienen en los importadores, así como el accionar de la Sunat al momento de implementar lo ordenado por el Mincetur, toda vez que a nuestro criterio el Mincetur debe tener claro que una vez determinada una verificación de origen, y en caso de que esta sea negativa, es decir que los productos analizados no sean considerados originarios, debe optar entre cerrar el trato preferencial al exportador o cobrar tributos a los importadores, e incluso determinar si corresponde adicionalmente disponer algún tipo de sanción. Y Sunat, por su parte, debe tener en cuenta que no puede disponer acciones que vayan más allá de lo ordenado por el Mincetur, y menos aún puede ordenar acciones que infrinjan normas de carácter administrativo que ocasionen perjuicios indebidos a los importadores y usuarios de los acuerdos comerciales y tratados de libre comercio en general. 


\section{Referencias}

Morón Urbina, J.C. (2001). Comentarios a la Ley del Procedimiento Administrativo General. Lima: Gaceta Jurídica.

\section{Legislaciones}

Acuerdo de Promoción Comercial Perú-Estados Unidos

2009 Capítulo cuatro. Reglas de origen y procedimientos de origen. 01 de febrero de 2009.

Congreso de la República del Perú

2001 Ley n. ${ }^{\circ}$ 27444. Ley del Procedimiento Administrativo General. 11 de abril de 2001.

Ministerio de Comercio Exterior y Turismo

2009 Decreto Supremo n. ${ }^{\circ}$ 001-2009-Mincetur. 15 de enero de 2009.

Ministerio de Comercio Exterior y Turismo

2009 Decreto Supremo n. ${ }^{\circ}$ 003-2009-Mincetur. 15 de enero de 2009. 